\title{
ESTRATÉGIAS JURÍDICAS DAS EMPRESAS DO SEGMENTO MINERÁRIO PARA REDUZIR OS IMPACTOS DA TERCEIRIZAÇÃO NO SETOR: ESTUDO DO CASO DO PROJETO MINAS-RIO
}

\section{LEGAL STRATEGIES OF MINING COMPANIES TO REDUCE THE IMPACT OF OUTSOURCING CONTRACTS: CASE STUDIE OF MINAS-RIO PROJECT}

\author{
Maria Tereza Fonseca Dias ${ }^{1}$ \\ Nayara Campos Catizani Quintão ${ }^{2}$
}

\section{RESUMO}

O presente trabalho trata das estratégias jurídicas a serem adotadas pelas empresas minerárias visando reduzir os efeitos da terceirização da atividade minerária na região de Conceição do Mato Dentro, Alvorada de Minas e Dom Joaquim, em Minas Gerais. Para delimitar o objeto do estudo, utilizou-se de pesquisas bibliográficas e como referencial teórico as bases traçadas pelo Programa Cidade e Alteridade. Quanto às propostas para a solução do problema, concluiu-se pela prática de gestão ligada ao "compliance" nas empresas e a contratação de apólice de seguro como meio coibir a prática quanto à terceirização ilegal ou ilícita.

Palavras-chave: Mineração; Estratégias jurídicas das organizações; Terceirização; Projeto Minas-Rio; Cidade e Alteridade

\section{ABSTRACT}

This paper deals with the legal strategies to be adopted by mining companies to reduce the effects of outsourcing of mining activity in the region of Conceição do Mato Dentro, Alvorada de Minas and Dom Joaquim, Minas Gerais, Brazil. To delimit the object of study, we used bibliographic research and theoretical reference the bases outlined by the City and Otherness Program. As for the proposals for the solution of the problem, concluded the practice management connected to "compliance" in business and hiring insurance policy as a means to curb the practice as illegal or unlawful outsourcing.

\footnotetext{
${ }^{1}$ Mestre e doutora em Direito Administrativo pela Universidade Federal de Minas Gerais - UFMG, (Brasil). Professora da UFMG e dos cursos de graduação e Mestrado em Direito da Universidade Fumec. Pesquisadora de Produtividade do CNPq.

E-mail: mariaterezafdias@yahoo.com.br

${ }^{2}$ Mestranda em Direito pela Fundação Municipal para Educação Comunitária - FUMEC, (Brasil). Especialista em Direito Processual pela PUC-MG. Advogada; Bolsista do CNPq do Projeto Impactos da Mineração nas regiões de Dom Joaquim e Alvorada de Minas.
} 
Keywords: Mining; Legal strategies of organizations; outsourcing; Minas-Rio Project; City and Otherness

\section{INTRODUÇÃO}

O presente estudo visa abordar os principais impactos provenientes da mineração no tocante aos seus desdobramentos na seara trabalhista, entre os quais se destacam aqueles provenientes do processo da terceirização no setor minerário. O fenômeno foi estudado a partir do levantamento de ações executórias na Justiça do Trabalho que se desencadearam após a instalação do empreendimento ligado a extração do minério de ferro na região de Conceição do Mato Dentro, Alvorada de Minas e Dom Joaquim, em Minas Gerais, do Projeto Minas-Rio.

Decerto que tal empreendimento, alavancado pela multinacional Anglo American, refere-se à instalação de um mineroduto, nas cidades em destaque, com a finalidade de extração de minério de ferro que está sendo escoado até o porto de Açu, em São João da Barra, no Estado do Rio de Janeiro.

O Sistema Minas-Rio tem importância estratégica tanto para a mineradora - quarta maior do mundo, que tem como objetivo uma participação de $10 \%$ no mercado mundial de minério de ferro até 2016 - quanto pelos Estados de Minas Gerais e Rio de Janeiro que viram no projeto uma oportunidade para alavancar o desenvolvimento regional ${ }^{3}$.

Segundo Becker e Pereira, a mina de Sapo-Ferrugem, instalada em Conceição do Mato Dentro, conta com vida útil em torno de 40 anos e reservas de 1,5 bilhões de toneladas de matéria-prima, cujo teor de óxido de ferro (Fe2O3) é de 37,9\%. Da unidade de beneficiamento há possibilidade de produção de 26,5 milhões de toneladas de minério de ferro por ano ${ }^{4}$. A destinação do minério é o mercado externo, que cresceu significativamente nos últimos anos

\footnotetext{
${ }^{3}$ Cf. PORTO, Eduardo. Terreno minado. Época Negócios, São Paulo, 5 abr. 2010. Disponível em: <http://epocanegocios.globo.com/Revista/Common/0EMI131170-16642,00- TERRENO+MINADO.html>. Acesso em: 24 set 2016; BRASIL MINERAL. Anglo quer expandir produção com projetos no Brasil. São Paulo, 16 dez. 2009. Disponível em: <http://www.brasilmineral.com.br/BM/default.asp?COD=4637\&busca=\&numero=4 32>. Acesso em: 24 set 2016.
}

\footnotetext{
${ }^{4}$ BECKER, Luzia Costa; PEREIRA, Denise de Castro. O Projeto Minas-Rio e o desafio do desenvolvimento territorial integrado e sustentável: a grande mina em Conceição do Mato Dentro (MG). In: FERNANDES, Francisco Rego Chaves; ENRÍQUEZ, Maria Amélia Rodrigues da Silva; ALAMINO, Renata de Carvalho Jimenez (Eds). Recursos Minerais \& Sustentabilidade Territorial: grandes minas. v. 1. Rio de Janeiro: CETEM/MCTI, 2011. Disponível em: <http://www.cetem.gov.br/workshop/pdf/vollgrandesminas.pdf> Acesso em: 23 set. 2016.
} 
graças à explosão do preço provocada pela demanda chinesa ${ }^{5}$, cuja matéria-prima explorada destina-se a produção de aço, ferramentas, máquinas, veículos de transporte, linhas de transmissão de energia elétrica, como elemento estrutural para a construção de edifícios e casas, além de possuir uma infinidade de outras aplicações.

Nesta seara, em que pese a chegada de um empreendimento minerário em uma localidade mexer com a vida das pessoas, com o ritmo das cidades e com o meio ambiente, também gera recursos que movimentam a economia local, viabilizam investimentos em saúde, educação, infraestrutura, e principalmente criam empregos, oportunidades de novos negócios, programas produtivos com as comunidades, abrem perspectivas para a população e ampliam horizontes.

Todavia, a par de todas as mudanças ligadas aos efeitos positivos e de cunho promissor, verifica-se dentre tantos outros impactos gerais, que o ambiente da mineração é caracterizado por poucos trabalhadores assegurados pelo regime jurídico da Consolidação das Leis do Trabalho (CLT), devido ao grande número de trabalhadores terceirizados, cuja organização dos sindicatos regionais aliada às mineradoras e a insuficiência fiscalizatória dos órgãos públicos municipais, tem gerado situações de alta gravidade a integridade física dos empregados-

Neste particular, destaca-se que a atividade da mineração, notadamente no segmento de extração do minério de ferro, tem se mostrado a mais letal para os trabalhadores no Brasil, haja vista as denúncias constantes quanto aos casos de mutilação, morte e doenças, de modo que o Estado de Minas Gerais compreende um dos mais perigosos locais para acidentes fatais no trabalho, o que se observa a partir de dados obtidos apresentados pela Fundação Jorge Duprat Figueiredo de Segurança e Medicina do Trabalho (Fundacentro) e Confederação Nacional Dos Trabalhadores na Indústria (CNTI), em pesquisa inédita que mapeia a saúde do trabalhador do setor mineral. A pesquisa mostra que de cerca de 137 mil trabalhadores formais (2012) do quadrilátero ferrífero, de Minas Gerais, quase 2 mil sofreram acidentes de trabalho. ${ }^{6}$

\footnotetext{
${ }^{5}$ ANGLO AMERICAN. Anglo American participa da Exposibram. Disponível em:

<http://www.angloamerican.com.br/aa_br/media/releases/2009pr/2009-08-21/>. Acesso em: 23 set 2016.

${ }^{6}$ SALIM, Celso; EMIDIO, Aline Riquetti Campos; ROCHA, Paula Mendes Werneck da. Identificação, mensuração e análise dos acidentes, doenças e mortes no setor mineral: construção de modelo de monitoramento das condições de trabalho e saúde dos trabalhadores das minerações. Belo Horizonte: Fundacentro / CNI, 2013. (Relatório de Pesquisa).Disponível em:

<http://ftp.medicina.ufmg.br/osat/arquivos/RelatorioAt_30092014.pdf>. Acesso em: 24 set. 2016. p. 68.
} 
Fato é que apesar da licença prévia para a exploração do minério de ferro na região de Conceição do Mato Dentro ter sido concedida em dezembro de $2008^{7}$ e a chegada expressiva de trabalhadores ter ocorrido após a concessão da primeira licença de instalação, em dezembro de 2009, o processo de intensificação do setor terceirizado ocorreu em meados de 2010, de modo que número volumoso de trabalhadores passou a se alojar nos referidos municípios e em áreas limítrofes.

Desse modo, tendo em vista a necessidade de se avaliar os impactos da atividade minerária e as mudanças proporcionadas no contexto urbano, foi empreendido um estudo para investigar os impactos sociais da mineração no âmbito da Justiça do Trabalho no período de 2011 a 2015 referentes aos municípios em destaque.

Para a análise dos principais problemas sociais relativos ao direito material do trabalho enfrentados, foi utilizado como referência teórica as bases traçadas quanto nas pesquisas de campo realizadas pelo Programa Cidade e Alteridade, que possibilitaram medir a gravidade das condições econômicas e sociais estendidas locais. Além dessas informações, foram extraiu dados de certidões ativas referentes a demandas trabalhistas no sítio do TRT da $3^{\text {a }}$ Região.

Logo, o presente estudo se justifica ante a necessidade de conhecimento quanto à realidade ambiental e socioeconômica oriunda da atividade da mineração do minério de ferro nas regiões selecionadas, que ainda vem respondendo por centenas de empregos diretos e indiretos. O Projeto Minas-Rio, em que pese ser um megaempreendimento que tem mudado a vida das comunidades locais, geral impacto social significativo na seara trabalhista, vez que a empresa responsável está envolvida em diversas ações em juízo, entre as quais encontra-se o tema da terceirização. Levantamento realizado no sítio do TRT $3^{\text {a }}$ Região revela que, até o presente momento, a empresa Anglo American responde cerca de 195 processos físicos e 121 processos eletrônicos.

Assim, o objetivo geral do trabalho é compreender os aspectos da produção de minério de ferro e os principais impactos desta atividade no campo laboral e responder ao

\footnotetext{
${ }^{7}$ GUSTIN, Miracy Barbosa de Sousa; SANTOS, Boaventura de Sousa. Impactos da Mineração na região de Conceição do Mato Dentro. Projeto Internacional de Pesquisa Cidade e Alteridade, iniciativa conjunta da UFMG, da UFV, da UI e do CES/UC. Disponível em: <http://cimos.blog.br/wpcontent/uploads/2013/08/RELAT\%C3\%93RIO-5_CONCEI\%C3\%87\%C3\%83O-DO-MATO-DENTRO.pdf >. Acesso em: 24 set 2016.
} 
seguinte questionamento: que estratégias jurídicas podem ser adotadas pelas companhias mineradoras visando reduzir o impacto da terceirização no setor?

A adoção de uma ampla política de terceirização movimentou denúncias às Delegacias do Trabalho e ao Ministério Público do Trabalho quanto à vulnerabilidade no tocante as condições de trabalho que os empregados foram submetidos no momento ápice do processo de viabilização da mina de extração do minério de ferro e instalação do mineroduto.

\section{A ATIVIDADE MINERÁRIA NO PAÍS E NO PROJETO MINAS-RIO}

\subsection{Formação e desenvolvimento da atividade mínero-metalúrgica nacional}

A mineração faz parte da história do Brasil desde os tempos de sua colonização. A narrativa conhecida sobre a trajetória econômica do país até o Século XX é marcada pela exploração de recursos naturais e exportação dessas commodities para a metrópole, e desta para toda a Europa. Com a descoberta de jazidas de ouro em meados do Século XVIII, a economia açucareira, baseada na plantation da cana-de-açúcar, foi vendo a atividade mineradora assumir um protagonismo cada vez maior na produção econômica. A exploração mineral não contava com tecnologia de ponta e era sustentada por mão-de-obra escrava ${ }^{8}$.

Esse cenário faz parte do pano de fundo do povoamento e desenvolvimento de muitos municípios do interior de Minas Gerais, desde os mais conhecidos, por terem sido grandes centros auríferos, como Ouro Preto e Mariana, mas também de centros urbanos menores que se viram em decadência com o declínio do ciclo do ouro. O contexto da exploração das minas de ouro no Século XVIII, quando os achados já não eram tão abundantes, foi marcado pelo trânsito volumoso de pessoas e mercadorias, levando à ocupação de novas terras mineiras. Assim, muitas expedições passaram pela região em que hoje se insere o município de Conceição do Mato Dentro9.

Em 1702, uma bandeira segue para o sul do Serro-Frio, descobrindo Itapanhoacanga e, em seguida, encontrando ouro. Essa descoberta fez surgir os arraiais de

\footnotetext{
${ }^{8}$ TÔRRES, Mariana Abreu. Histórias de água e minério: os efeitos do Projeto Minas-Rio em Água Quente, Conceição do Mato Dentro. Disponível em: <http://conflitosambientaismg.lcc.ufmg.br/wpcontent/uploads/2014/12/Monografia-Marina-Abreu-Efeitos-do-Projeto-Minas-Rio.pdf >. Acesso em: 24 set 2016. p. 25.

${ }^{9}$ Idem. p. 25.
} 
Tapera, Córregos, Morro do Pilar e Conceição. ${ }^{10}$ Ela se constituiu enquanto sede municipal em 1842, tendo sido a $37^{\mathrm{a}}$ vila da província de Minas Gerais. Nesse ano, as minas já haviam se enfraquecido e a vila contava com pouco de mais de 200 (duzentos) casas, muitas abandonadas ou em ruína.

Na primeira metade do Século XIX surgiram as primeiras fábricas e companhias de mineração no Estado de Minas Gerais com produções significativas, com os empreendimentos da Fábrica de Ipanema, em 1810, em Araçoiaba, e da Real Fábrica de Ferro do Morro do Pilar, em 1814. No entanto, só foi depois da independência do Brasil, em 1822, e com a introdução de uma nova Constituição, em 1824, que as autoridades locais aprovaram leis para regulamentar a pesquisa e lavra de jazidas minerais ${ }^{11}$.

No entanto, destaca Costa, "Conceição, como todas as comunidades surgidas por efeito da mineração, sofreu as consequências do colapso que se foi verificando na exploração das minas"12. Ocorre que quase dois séculos depois, a mineração volta a fazer parte da história de Conceição do Mato Dentro, compondo nova guinada da exploração mineral brasileira, estimada 43 (quarenta e três) bilhões de dólares para o ano de $2014^{13}$.

A mineração de ferro passou então a ser a principal atividade extrativa do país, de modo que o Brasil possui a quinta maior reserva do mundo, com um total estimado de 40 (quarenta) a 50 (cinquenta) bilhões de toneladas, e é o segundo maior produtor neste segmento.

Todavia, em face da larga escala com que tem se mostrado no cenário do desenvolvimento industrial, as restrições ao uso do capital estrangeiro quanto às concessões e autorizações para explorações do minério de ferro foram removidas por meio de Emenda Constitucional, sendo que desde 1996 houve a intensificação da entrada de investimentos de multinacionais, o que vem desencadeando o crescimento do setor e incentivando a discussão acerca regras sobre o desenvolvimento da mineração, considerando grande impacto que a

\footnotetext{
${ }^{10}$ COSTA apud TORRES, Op. Cit. p.26

11 FONSECA, Marcelo da. Nossa história: Minas Gerais é o berço da legislação mineral. Disponível em: <http://www.em.com.br/app/noticia/politica/2014/11/08/interna_politica,587993/nossa-historia-minas-gerais-eo-berco-da-legislacao-mineral.shtml>. Acesso em: 24 set 2016.

12 COSTA apud TÔRRES, Mariana Abreu. Histórias de água e minério: os efeitos do Projeto Minas-Rio em Água Quente, Conceição do Mato Dentro. Disponível em: <http://conflitosambientaismg.lcc.ufmg.br/wp content/uploads/2014/12/Monografia-Marina-Abreu-Efeitos-do-Projeto-Minas-Rio.pdf >. Acesso em: 24 set 2016., p.26).

${ }^{13}$ TÔRRES, Mariana. Op. Cit.
} 
atividade causa na rotina das populações que convivem com a exploração próxima, ou até dentro, de seus municípios.

Neste cenário foi que surgiu o complexo minerário Minas-Rio, empreendimento que, conforme informação do Instituto Brasileiro de Mineração (IBRAM) inclui uma mina de minério de ferro e unidade de beneficiamento em Conceição do Mato Dentro e Alvorada de Minas, em Minas Gerais; mineroduto com 529 (quinhentos e vinte e nove) km de extensão e que atravessa 33 (trinta e três) municípios mineiros e fluminenses; e o terminal de minério de ferro do Porto de Açu, localizado em São João da Barra (RJ). ${ }^{14}$

\subsection{Projeto Minas-Rio: múltiplas faces, um único projeto}

As montanhas que cercam cidade de Conceição do Mato Dentro, em Minas Gerais, contêm ricas jazidas de minério de ferro e as sementes de um dos maiores acervos do orçamento da história da mineração. Em agosto de 2008, a Anglo American criou a Anglo Ferrous Brazilatual Unidade de Negócio Minério de Ferro Brasil - formada a partir da integração do Projeto Minas-Rio (extração e beneficiamento de minério de ferro, com capacidade de produção de 26,5 milhões de toneladas por ano) e do Sistema Amapá (compreendendo a mina, a ferrovia e o porto).

No mês de dezembro de 2009, o conglomerado britânico Anglo American iniciou, com o aval do Estado, a implementação do empreendimento minerário Minas-Rio, cujo projeto consistiu na instalação de uma mina a céu aberto e estruturas adjacentes em Conceição do Mato Dentro e dois municípios vizinhos em Minas Gerais, além de um mineroduto de 525 (quinhentos e vinte e cinco) $\mathrm{km}$ de extensão para o transporte do minério até o litoral do Rio de Janeiro, no Porto de Açu. Além disso, o grupo detém 49\% (quarenta e nove por cento) do terminal de minério do porto de Açu (em parceria com a LLX, de Eike Batista) localizado em São João da Barra, no Rio de Janeiro ${ }^{15}$.

\footnotetext{
${ }^{14}$ ANGLO AMERICAN. Polícia de Conceição do Mato Dentro Inaugura Quartel com o apoio da Anglo American. Disponível em: <http://www.ibram.org.br/150/15001002.asp?ttCD_CHAVE=256460>. Acesso em: 24 set. 2016.

15 TÔRRES, Mariana Abreu. Histórias de água e minério: os efeitos do Projeto Minas-Rio em Água Quente, Conceição do Mato Dentro. Disponível em: <http://conflitosambientaismg.lcc.ufmg.br/wp content/uploads/2014/12/Monografia-Marina-Abreu-Efeitos-do-Projeto-Minas-Rio.pdf>. Acesso em: 24 set 2016.
} 
Trata-se de Projeto de grande porte, em uma região de alta vulnerabilidade social e ambiental, potencial gerador de grandes conflitos. Dadas estas características, sua implantação foi tortuosa, eis que sua efetividade, tida como modelo para o desdobramento de inúmeras outras atividades não foi de toda viabilizada desde o início da sua implantação.

Tal fato foi alvo de questionamento e discussão na $29^{a}$ Reunião Ordinária do COPAM (URC/Jequitinhonha), realizada em Diamantina, no dia 11 de dezembro de 2008. Ora, desde o início, o "Minas-Rio" gerou conflitos ambientais e sociais nas imediações da Serra da Ferrugem, ao longo do trajeto do mineroduto e próximo ao local de construção do porto. ${ }^{16}$ Todavia, ainda assim, grande parte da população apoiou a iniciativa esperando a oferta de emprego e, principalmente, a chegada do desenvolvimento. ${ }^{17}$

No início de 2006, inúmeros jornais de Minas Gerais como o "Tempo" e o “Globo" passaram a anunciar o novo ciclo da mineração em Conceição do Mato Dentro e as primeiras manchetes demonstravam otimismo. ${ }^{18}$ Todavia, em 2010, o tom das notícias já não era o mesmo, posto que estampado nos jornais comentários gerais de que a Mineração na Serra da Ferrugem acirrou disputas por terras, cujos preços tinham sido decididos pela capacidade dos moradores resistirem ao avanço da atividade.

Desde então, são os problemas e os conflitos que passaram a prevalecer. Cite-se, como exemplo, os inúmeros questionamentos feitos pelo Ministério Público quanto à licença da linha de transmissão autorizada, a escassez da água (esta necessária ao escoamento do minério ao longo da extensão do mineroduto), o resgate de trabalhadores estrangeiros que trabalhavam em condições degradantes, inúmeras autuações por trabalho análogo ao regime escravocrata, a invasão de terrenos, o aumento de mães solteiras, aumento da violência, perda

\footnotetext{
${ }^{16}$ ZHOURI, Andréa. Estudo de Atualização das Áreas de Influência (AI) do Projeto Minas-Rio Mineração, elaborado pela empresa de consultoria Ferreira Rocha Gestão de Projetos Sustentáveis. Grupo de Estudos em Temáticas Ambientais (GESTA - UFMG). Disponível em:

<https://webcache.googleusercontent.com/search?q=cache:NQM_Ck1RjAJ:https://conflitosambientaismg.lcc.uf mg.br/wp-content/uploads/2015/09/Parecer-GESTA-sobre-Relat\%25C3\%25B3rio-Ferreira-Rocha-2014VF.pdf+\&cd=1\&hl=pt-BR\&ct=clnk\&gl=br>. Acesso em: 24 set 2016.

${ }^{17}$ GAZIZINELLI, Gustavo; RIBEIRO, Gabriel; GENEROSO; Patrícia. Minerodutos: um cheque em branco para o desenvolvimento do país. Entrevista concedida por e-mail a IHU On-Line, 07 jan 2016. Disponível em: $<$ http://cartamaior.com.br/?/Editoria/Meio-Ambiente/Minerodutos-um-cheque-embranco-para-o-desenvolvimento-do-pais/3/35281>. Acesso em: 24 set 2016.

${ }^{18}$ DAMATO, Frederico. Vale estuda explorar reserva em Conceição do Mato Dentro. O Tempo, Minas Gerais, 25 abr 2008. Disponível em: <http://www.otempo.com.br/capa/economia/vale-estuda-explorar-reserva-emconcei\%C3\%A7\%C3\%A3o-do-mato-dentro-1.266474>. Acesso em: 24 set 2016.
} 
da identidade cultural e dentre tantos outros que foram alvo de um detalhado estudo no Programa Cidade e Alteridade desenvolvido pela Universidade Federal de Minas Gerais e instituições parceiras ${ }^{19}$.

Nesse contexto, saliente-se que no dia 17 de junho de 2015, os problemas gerados pelo empreendimento minerário foram alvo de destaque no jornal "Estado de Minas", sendo a reportagem principal desta data ilustrada pelo caso de Conceição, no tocante aos males do crescimento, em que no primeiro parágrafo lia-se a seguinte afirmativa: "O crescimento econômico, a criação de oportunidades de emprego e a geração de renda são sonhos de toda cidade do interior de Minas ou em qualquer outro Estado. Porém, os efeitos colaterais desse desenvolvimento nem sempre são esperados e raramente contam com planejamento." 20

Fato é que a principal crítica a envolver toda a tratativa ligada questão do desenvolvimento e emprego da atividade minerária esteve relacionada ao manto descoberto com que os prestadores de serviços passaram a desfavorecer os trabalhadores que passaram a executar suas tarefas sem qualquer amparo das normas celetistas.

A isso tudo somam-se as investigações de caráter trabalhista, tendo em vista as greves de operários da LLX e da Anglo American, que reivindicavam melhorias salariais, adicional de $30 \%$ de periculosidade, participação nos lucros e resultados, seguro de vida e adaptações no alojamento". ${ }^{21}$

\section{IMPACTOS TRABALHISTAS ADVINDOS COM PROJETO MINAS-RIO SOB O ENFOQUE DA TERCEIRIZAÇÃO}

\footnotetext{
${ }^{19}$ GUSTIN, Miracy Barbosa de Sousa; SANTOS, Boaventura de Sousa. Impactos da Mineração na região de Conceição do Mato Dentro. Relatório sobre os impactos da mineração e as mudanças no contexto Urbano de Conceição do Mato Dentro, Brasil Relatório Final. Belo Horizonte, 2014. Disponível em: $<$ http://docplayer.com.br/1858332-Relatorio-sobre-os-impactos-da-mineracao-e-as-mudancas-no-contextourbano-de-conceicao-do-mato-dentro-mg-brasil-relatorio-final.html>. Acesso em: 24 set 2016.
}

${ }^{20}$ FERREIRA, Pedro; PARANAÍBA, Guilherme. As cidades crescem, a segurança diminui. Estado de Minas, Minas Gerais, 17 jun 2015. Disponível em: <

http://webcache.googleusercontent.com/search?q=cache:YpUzdKj3cIUJ:impresso.em.com.br/app/noticia/cadern os/gerais/2015/06/17/interna_gerais,153268/as-cidades-crescem-a-seguranca-diminui.shtml+\&cd=1\&hl=ptBR\&ct=clnk\&gl=br> . Acesso em: 25 set 2016.

${ }^{21}$ TRABALHADORES do Porto Açu entram em greve. Portal G1. Disponível em: <http://g1.globo.com/economia/noticia/2011/03/trabalhadores-do-porto-do-acu-entram-em-greve.html>. Acesso em: 24 set 2016. 
O setor da mineração está em quarto lugar no que se refere ao número de acidentes de trabalho no país e é o segundo em taxa de mortalidade por acidente de trabalho. Os riscos a que os trabalhadores da mineração são submetidos incluem exposição à poeira, manejo de equipamentos sem proteção, carga de trabalho excessiva e movimentos repetitivos, dentre outros. ${ }^{22}$

E em meio à atividade extravista e, considerando os dados coletados ao longo da pesquisa empreendida, verificou-se que um dos problemas ligados ao desencadeamento da precarização das condições de trabalho no setor minerário no Projeto Minas-Rio, tratava-se da prática irrestrita ligada à terceirização, em que fundamentalmente permitiu-se que os prestadores de serviços explorassem atividades preponderantes relacionas com a atividade econômica principal do tomador de serviços, no caso, a empresa Anglo American.

Quanto à terceirização ilegal ou ilícita, parte-se do pressuposto de que é aquela que se refere à locação permanente de mão-de-obra, que pode dar ensejo a fraudes e a prejuízo aos trabalhadores.

E quanto ao enfoque do presente trabalho, observa-se ter ocorrido na implantação do Sistema Minas-Rio violação direta a leis nacionais e pactos internacionais de direitos, porquanto em duas ocasiões a empresa Anglo American e empresas por ela contratadas para prestar serviços na instalação das estruturas do referido projeto foram autuadas por trabalho em condições análogas à escravidão, conforme amplamente noticiado nos jornais de circulação em âmbito nacional. ${ }^{23}$

A primeira delas, em novembro de 2013, refere-se ao caso de 172 trabalhadores, 100 dos quais haitianos, alojados em residências precárias, vivendo e trabalhando em condições degradantes, com poucas horas de repouso e alimentação de baixa qualidade. A autuação resultou em um termo de ajustamento de conduta com pagamento de $\mathrm{R} \$ 100.000,00$ de dano moral coletivo. No segundo caso, autuado em abril de 2014, foram encontrados 185 trabalhadores contratados pela Anglo American e por suas terceirizadas em situação análoga à

\footnotetext{
${ }^{22}$ HAJE, Lara. Mortalidade por acidente de trabalho em setor de mineração é muito alta, diz pesquisador, 2014. Câmara Notícias. Disponível em: < http://www2.camara.leg.br/camaranoticias/noticias/ECONOMIA/473712MORTALIDADE-POR-ACIDENTE-DE-TRABALHO-EM-SETOR-DE-MINERACAO-E-MUITO-ALTA,DIZ PESQUISADOR.html>. Acesso em: 24 set. 2016.
}

${ }^{23}$ PEDROSA, Ana Paula; ARIADNE, Queila. Anglo American é autuada por trabalho análogo à escravidão. O Tempo, Belo Horizonte, 24/04/2014. Disponível em: < http://www.otempo.com.br/capa/economia/angloamerican-\%C3\%A9-autuada-por-trabalho-an\%C3\%A1logo-\%C3\%A0-escravid\%C3\%A3o-1.827736>. Acesso em: 24 set 2016. 
escravidão. Na ocasião, foram denunciadas jornadas exaustivas de trabalho, de até $18 \mathrm{~h}$ por dia, redução de horários de almoço a menos de vinte minutos, bem como mais de 200 horas extras mensais. $^{24}$

E além do trabalho análogo à escravidão, o MTE (Ministério do Trabalho e Emprego) classificou como ilícita a terceirização da atividade a empresa Tetra Tech. No entendimento do órgão, os 435 operários que trabalhavam para a Tetra Tech desempenhavam atividade-fim e, portanto, deveriam ser contratados diretamente pela Anglo American. Desses, 67 eram submetidos a condições análogas às da escravidão..$^{25}$

Outrossim, a partir de consulta no sítio do TRT da $3^{\text {a }}$ Região, verificou-se que atualmente há 195 processos físicos e 121 processos eletrônicos que envolvem diretamente a empresa Anglo American na região, sendo que 80\% tratam de irregularidades criadas pelas prestadoras de serviços, sem que se considere em tal relação acordos firmados em juízo; arquivamento de autos;exclusão da tomadora de serviços do polo passivo e ações de consignação em pagamento, bem como processos oriundos de mandados de segurança, embargos de terceiros e inquérito para a apuração de falta grave.

Fato é que o problema da terceirização ilícita no segmento minerário é de suma gravidade, já que assim como destaca coordenador do Projeto de Combate ao Trabalho Análogo ao de Escravo da Superintendência Regional do Trabalho e Emprego em Minas Gerais (SRTEMG), Marcelo Campos ${ }^{26}$, muitos trabalhadores não se sentem enquadrados em trabalho escravo porque, ao contrário do que acontecia até o século XIX, eles recebem pelo serviço, o que cria uma falsa ilusão quanto à licitude em relação às práticas de gestão apresentadas, demandando

\footnotetext{
${ }^{24}$ WROBLESKI, Stefano. Fiscalização volta a flagrar escravidão em megaobra da Anglo American. Repórter Brasil, 17/05/2014. Disponível em: <http://reporterbrasil.org.br/2014/05/fiscalizacao-volta-a-flagrar-escravidaoem-megaobra-da-anglo-american/>; WROBLESKI, Stefano. Imigrantes haitianos são escravizados no Brasil. Repórter Brasil, 23/01/2014; <http://reporterbrasil.org.br/2014/01/imigrantes-haitianos-sao-escravizados-nobrasil/>; MINERADORA é autuada por trabalho análogo à escravidão em Minas. G1 MG, 25/04/2014 <http://g1.globo.com/minas-gerais/noticia/2014/04/mineradora-e-autuada-por trabalho-analogo-escravidao-emminas.html>; PEIXOTO, Paulo. Gigante da mineração é autuada por trabalho análogo à escravidão em MG. Mercado. Folha de S. Paulo, 24/04/2014. Disponível em: <http://www1.folha.uol.com.br/mercado/2014/04/1445055-gigante-da-mineracao-e-autuada-por-trabalhoanalogo-a-escravidao-em-mg.shtml>.Acesso em: 24 set 2016.
}

${ }^{25}$ PEDROSA, Ana Paula; ARIADNE, Queila. Anglo American é autuada por trabalho análogo à escravidão. $\mathbf{O}$ Tempo, Belo Horizonte, 24/04/2014. Disponível em: < http://www.otempo.com.br/capa/economia/angloamerican-\%C3\%A9-autuada-por-trabalho-an\%C3\%A1logo-\%C3\%A0-escravid\%C3\%A3o-1.827736>. Acesso em: 24 set 2016.

${ }^{26}$ Idem 
que se atente para a criação de um novo modelo de governança nas empresas terceirizadas, que possa evitar a consubstanciação de atos ilícitos.

\section{ASPECTOS GERAIS LIGADOS A TERCEIRIZAÇÃO}

Nos dias atuais a terceirização vem sendo amplamente discutida no Brasil, haja vista se tratar de um tema de grande relevância na esfera trabalhista.

A terceirização nada mais é do que uma forma de organização estrutural, que permite a uma empresa, seja ela privada ou governamental, transferir a uma outra empresa, determinado serviço que esteja ligado a sua atividade-meio, a fim de proporcionar maior disponibilidade de recursos para o desenvolvimento de atividade-fim, sem que, contudo, haja os elementos que caracterizam a relação de emprego, tais como: subordinação, pessoa física, pessoalidade, não eventualidade e onerosidade.

Nesse aspecto, Rodolfo Pamplona ${ }^{27}$ diz que o instituto da terceirização nada mais é do que a "[...] transferência do segmento ou segmentos do processo de produção da empresa para outros de menor envergadura, porém de maior especialização na atividade transferida."

Já no que tange ao setor da mineração, a terceirização ou outsorcing é um procedimento antigo, empreendido como prática recorrente no mercado de trabalho por grandes empresas do setor minerário que procuram terceirizar certas áreas do seu segmento, notadamente a lavra, o processamento, a metalurgia, a data mining, a aquisição de dados (geofísica, geoquímica etc..), além dos aspectos ligados a manutenção, alimentação, limpeza e refeitório.

Esse processo é visto com bons olhos pelos mineradores, que podem focar naquelas atividades mais importantes que são fundamentais à sobrevivência da empresa, de forma que hoje há possibilidade de se montar e operar uma mina com quase $100 \%$ dos empregados terceirizados.

Todavia, tal prática minerária tem sido alvo de reprimenda pelos órgãos de fiscalização no tocante ao desvirtuamento com o qual a tomadora dos serviços terceirizados tem se eximido das responsabilidades contratuais, porquanto apesar de se baratear os custos; existir

\footnotetext{
${ }^{27}$ PAMPLONA, Rodolfo. Terceirização e responsabilidade patrimonial da administração pública. Salvador. Revista Diálogo Jurídico, 2002, nº 11, p. 36.
} 
o aumento da velocidade operacional; haver maior flexibilidade e possibilidade quanto às vantagens competitivas, não há obrigatoriedade das prestadoras de serviço se adequarem à governança corporativa da contratante, o denominado compliance.

Neste aspecto, o que se observa é que inexiste a aproximação das regras das empresas terceirizadas aos princípios fundamentais do gerenciamento da contratante.

Ora, a complexidade do cenário empresarial e regulatório está aumentando significativamente.As organizações expandiram consideravelmente e cada dia mais enfrentamconstantes mudanças. Além disso, há exposição negativa da imagem das empresas tomadoras de serviçosgerada por fatos associados à corrupção e problemas trabalhistas oriundos da inobservância quanto aos preceitos normativos ligados à proteção ao trabalhador, dentre outras várias falhas de integridade organizacional.

Assim, o compliance, termo em inglês, oriundo do verbo tocomply, tem conduzido a uma necessidade de empreender um agir de acordo com uma regra, uma instrução interna, um comando ou um pedido, como forma de se transmitir a intenção de agir como lei ou norma.

Nas organizações brasileiras encontram-se áreas de compliance estruturadas com atuação voltada a procedimentos que visem o cumprimento das exigências legais, prevenção, detecção e combate a infrações além da disseminação de princípios éticos de integridade corporativa.

Além disso, reforça a necessidade de desenvolvimento de mecanismos internos de fiscalização e incentivo a denúncia, elaboração, aperfeiçoamento e disseminação dos códigos de ética e implementação de programas de integridade. Abordam-se os direcionamentos para a implantação do Programa de Integridade, o que conforme previsão legal (Lei n. ${ }^{\circ}$ 12.846/2013), diz respeito a sua importância e o caráter jurídico que terão para evitar e combater comportamentos corruptivos.

Com efeito, o compliance é tendência em governança que se vincula à realização de relações éticas e transparentes entre empresas e em suas interações com o setor público nacional e transnacional, de forma as ligações das empresas do setor privado devem e podem ser realizadas de forma transparente e íntegra.

Por isso, a empresa que se apresenta no mercado com uma política de compliance, devidamente consolidada e implantada possui um diferencial em detrimento das demais, principalmente no tocante ao mercado de ações ou nas relações com as instituições financeiras internacionais e nacionais. 


\section{MEIOS DE MINIMIZAR OS IMPACTOS TRABALHISTAS ADVINDOS DA MINERAÇÃO}

No cenário brasileiro a noção de compliance não é recente, mas certamente foi a Lei Anticorrupção (Lei n. ${ }^{\circ}$ 12.846/2013) que fez o tema ganhar maior relevância na mídia e ser uma preocupação para todos os âmbitos empresariais e não somente para as grandes corporações multinacionais. Contudo, o referido preceito normativo tem inicialmente um enfoque para tratar as relações entre o setor público e o privado, donde ver-se que a noção de compliance fica comprometida e reduzida a esse ponto, portanto vislumbra-se ser patente a necessidade de complementação da tratativa sob a vertente de novas ações que possuam correspondência com os temas que se busca viabilizar. ${ }^{28}$

Assim, dentro da presente análise, pretende-se demonstrar a necessidade de se implementar relações e atividades internas e externas a serem adotadas pelas empresas prestadoras e tomadoras de serviços, em ações regulatórias de cunho inibitório a evitar à adoção de práticas irregulares que visem inibir a precarização quanto as condições de trabalho que submetidos os trabalhadores terceirizados e minimizar os riscos jurídicos dentro da seara ligada ao direito material do trabalho.

Logo, sustenta-se, que não obstante ser terceirização uma boa escolha sob a ótica do setor minerário na camada empresarial quando se fala em especialização da prestação de serviços, desburocratização e de redução dos custos operacionais, há uma tendência crescente de práticas fiscalizatórias das organizações aplicadas pelo Ministério do Trabalho e Emprego que visam o combate a chamada terceirização "ilegal" por meio de ações repressivas contra atos manifestamente acabados.

Ocorre, todavia, que por pressões de mercados internacionais tem-se observado que organizações capitalistas estão cada vez mais predispostas a estabelecer medidas com o objetivo de prevenção e combate à corrupção. Percebe-se que o Brasil tem se esforçado nesta empreitada ser signatário de tratados e convenções, aonde vem assumindo ajustes perante organismos internacionais e na sanção de leis que tratam este compromisso.

\footnotetext{
${ }^{28}$ MORAIS, Flaviane Barros Bolzan de. Compliance e o cenário brasileiro após a regulamentação da lei anticorrupção. Disponível em:

<http://www.migalhas.com.br/dePeso/16,MI226699,31047Compliance+e+o+cenario+brasileiro+apos+a+regula mentacao+da+lei>.
} 
Portanto, um importante método a ser utilizado como forma de minimizar as ações estarrecedoras advindas do implemento em larga escala quanto a prática da terceirização no meio minerário, diz respeito a possibilidade de integrar boas práticas de “compliance” como ação preventiva a ser acompanhada de perto pelo órgãos ministeriais fiscalizatórios, em que o plano de medidas sob enfoque possa incluir a contratação de uma apólice de seguro que cubra eventuais prejuízos decorrentes de negócios irregulares do setor terceirizado de maneira a empreender uma gestão de terceiros no ambiente empresarial.

A proposta ao presente estudo quanto ao uso da apólice de seguro diz respeito a possibilidade de criação quanto a limites de responsabilidades às indenizações geradas por sinistro ocorridos, exclusivamente, durante a vigência dos contratos de prestação de serviços ligado aos agentes terceirizados. Assim, em tese, restaria entendido e acordado que para o presente seguro seria contratado como um limite de indenização isolado para as coberturas previstas que seriam estabelecidas por meio da gestão colaborativa, conforme respectivas cláusulas especiais que se fizerem contar do termo. Neste particular, todas as coberturas indicadas, possuiriam limites máximos de indenização, compondo um único limite deste contrato.

Por certo, tal premissa é adotada a partir do uso de analogia quanto à existência do "seguro de obra civil", que se presta a cobertura de danos acidentais de origens súbitas ocorridas durante todo o período da execução do contrato, bem como contra as perdas financeiras decorrentes de danos causados a terceiros ${ }^{29}$.

Ora, o Brasil está vivendo um momento muito peculiar. O aumento dos juros, inflação descontrolada e uma economia instável fazem com que se crie um novo pensamento tendente a incentivar novas práticas, mormente como tentativa de desafogar o Poder Judiciário, porquanto tal esfera não encontra arcabouço para amparar a contendo o enorme número de demandas trabalhistas que volta e meia engessam deslinde do movimento terminativo de ações.

Desse modo, o desencadeamento de ações ligadas aos princípios da prevenção e precaução, bem como aos princípios basilares do direito trabalhista, pautados pela Proteção ao Trabalhor, "In Dubio pro Operário", da Irrenunciabilidade dos Direitos, da Continuidade do Pacto Laborativo e da Primazia da Realidade, fazem com que a seara empresarial venha a desenvolver práticas de gestão administrativas internas como forma calcar as ações dos agentes

\footnotetext{
${ }^{29}$ SEGUROS da Construção. Disponível em:<http://www.ebanataw.com.br/roberto/seguros/segciv0.htm>.
} Acesso em: 25 set 2016. 
terceirizados e viabilizar com que se dê andamento à especialização quanto aos segmentos dos prestadores de serviços, possibilitando aumento da produção com menor custo e sem que exista a desrespeito às normas celetistas que tratam do maior respeito ao trabalhador, dando efetividade à vertente das demandas que tratam do Estado Democrático de Direito.

É imperioso, portanto, que não se realize reformas legislativas, por meio de leis que incorporem tanto premissas econômicas quanto ecológicas, mas sim que se inicie uma intensa atividade de adoção de medidas de prática educativa, de cunho preventivo, a fim de diminuir ou até mesmo sanar as falhas do mercado. A interação entre direito e economia resultará na prática que se volte na eficácia quanto à melhor alocação dos recursos, alcançando um desenvolvimento de meio ambiente laboral sustentável.

Neste aspecto, cumpre avaliar que as soluções sugeridas proporcionariam maior compreensão sobre a efetividade dos processos internos, eis que geraria a adoção de melhores práticas de gestão quanto aos agentes terceirizados, a partir de mecanismos de controle quanto à checagem dos serviços prestados e combate às fraudes e atos ilícitos, mormente ao fato de que possibilitaria antever a irregularidade a ser praticada, quando o plano de gestão fosse apresentado às unidades fiscalizatórias administrativas que atuam na esfera regulação de cunho inibitório.

\section{CONCLUSÃO}

Diante do atual cenário que assola o segmento da mineração, tem-se que a crise interligada as práticas quanto à terceirização ilegal clamam por um pedido de reforma efetiva a ser empreendida pelo meio empresarial de modo a se estabelecer novas normas comportamentais de cunho econômico e social que possam conter os efeitos deletérios dos agentes terceirizados, potenciais infratores que desencadeiam inúmeras demandas judiciais em manifesto prejuízo ao trabalhador.

Numa breve passagem quanto análise do desenvolvimento da instalação de minas de exploração de minério de ferro e implementação do mineroduto nas regiões compreendidas pelas cidades Conceição do Mato Dentro, Alvorada de Minas e Dom Joaquim, projeto atual e itinerante construídos dentro das matizes do sistema Minas-Rio, verificou-se a disseminação da terceirização como prática deletéria de desrespeito às normas trabalhistas, eis que inúmeros trabalhadores foram deixados a mercê da própria sorte tendo de se recorrer ao Judiciário como forma de fazer valer o mínimo de integridade quanto as suas condições empregatícias, o que 
muitas das vezes recai contra a responsabilidade do tomador de serviços e sobre aqueles que representam o figura do real empregador.

E da busca pela efetiva aplicação dos princípios preventivos, como forma de se evitar a insustentabilidade no tocante a prática da terceirização ilegal no segmento minerário à gerações futuras, defendeu-se o desenvolvimento de métodos ligados ao "compliance” aliados a inserção a criação do uso de apólice securitária como meio de viabilizar menor impacto tanto aquele que se submetem a condição de assalariados como aqueles que presente no desenvolvimento e explosão de atividade econômica de alta representatividade no cenário brasileiro.

Decerto que, diante da crescente expansão territorial, a aplicação de medidas coercitivas, utilizadas com o respaldo reparatório unicamente não tem surtido efeito satisfatório, mormente pelo fato de que a letalidade e o colapso mental a que vêm chegar o trabalhador em atividade ritmo intenso, não possuir correspondência em tal plano, o que leva crer que medidas preventivas a serem desenvolvidas como plano interno de gestão ligada à governança corporativa colaborativa possa ser uma saída a minimizar os malgrados efeitos da terceirização irregular.

Sendo assim, como forma de responder ao questionamento exposto, sustenta-se que há possibilidade de evitar o uso de práticas incidentes quanto à terceirização ilegal no setor minerário, haja vista que a adoção de ferramentas ligadas ao compliance e a realização de contratos de seguro possibilitam criar uma estratégia inibitória a ser aplicada no âmbito interno empresário, como se houvesse uma hierarquização normativa a ser seguida pela instituição.

Desse modo, o que se busca, em especial, na relevância da tutela ao trabalhador em meio aos pilares signatário do Estado Democrático de Direito, é particularmente, trazer uma política efetiva e abrangente, que, pautada nos institutos trabalhados, possibilitarão em demasiado o equilíbrio às relações empregatícias, para que, assim, a sustentação das medidas preventivas seja assegurada.

Desta feita, buscam-se possibilidades de combate a tais irregularidades, tendo por premissa a noção imposta pelos vetores dos princípios da boa-fé e do valor social dos contratos que devem emergir destas relações. É preciso considerar que nem todos que optam pela contratação de tal modalidade de prestação de serviços apresentam intuito preordenado de prática de regularidade quanto ao trabalho, razão pela qual parece salutar que, ao lado da ação repressiva do Judiciário trabalhista, há a possibilidade de atuação preventiva, em especial, no 
tocante aos esclarecimentos sobre o tema àqueles que pretendem fazer uso de modalidade peculiar de prestação de serviços.

\section{REFERÊNCIAS}

ANGLO AMERICAN. Polícia de Conceição do Mato Dentro Inaugura Quartel com o apoio da Anglo American. Disponível em:

<http://www.ibram.org.br/150/15001002.asp?ttCD_CHAVE=256460>. Acesso em: 24 set 2016.

ANGLO AMERICAN. Anglo American participa da Exposibram 2009. In: Site, Rio de Janeiro, 21 ago. 2009. Disponível em: http://www.angloamerican.com.br/aa_br/media/releases/2009pr/2009-0821/. Acesso em: 23 set 2016.

BACELAR, R.P. Nem só de mineração vive o Matodentro: a experiência de jovens em território de conflito ambiental. Tese de Doutorado, PPGP, Inst. de Psicologia, UFRJ, 2014. Orientação: Lucia Rabello de Castro.

BECKER, Luzia Costa; PEREIRA, Denise de Castro. O Projeto Minas-Rio e o desafio do desenvolvimento territorial integrado e sustentável: a grande mina em Conceição do Mato Dentro (MG). In: FERNANDES, Francisco Rego Chaves; ENRÍQUEZ, Maria Amélia Rodrigues da Silva; ALAMINO, Renata de Carvalho Jimenez (Eds). Recursos Minerais \& Sustentabilidade Territorial: grandes minas. v. 1. Rio de Janeiro: CETEM/MCTI, 2011. Disponível em: <http://www.cetem.gov.br/workshop/pdf/vollgrandesminas.pdf> Acesso em: 23 set. 2016.

BRASIL MINERAL. Anglo quer expandir produção com projetos no Brasil. São Paulo, 16 dez. 2009. Disponível em:

http://www.brasilmineral.com.br/BM/default.asp?COD=4637\&busca=\&numero=4 32. Acesso em: 24 set 2016 .

COSTA, J. R. Conceição do Mato Dentro: fonte da saudade. Belo Horizonte: Itatiaia, 1975.

DAMATO, Frederico. Vale estuda explorar reserva em Conceição do Mato Dentro. Jornal o Tempo, Minas Gerais, 25 abr 2008. Disponível em: <http://www.otempo.com.br/capa/economia/valeestuda-explorar-reserva-em-concei\%C3\%A7\%C3\%A3o-do-mato-dentro-1.266474>. Acesso em: 24 set 2016.

FERREIRA, Pedro; PARANAÍBA, Guilherme. As cidades crescem, a segurança diminui. Jornal Estado de Minas, Minas Gerais, 17 jun 2015. Disponível em: <

http://webcache.googleusercontent.com/search?q=cache:YpUzdKj3cIUJ:impresso.em.com.br/app/noti cia/cadernos/gerais/2015/06/17/interna_gerais,153268/as-cidades-crescem-a-seguranca-

diminui.shtml+\&cd=1\&hl=pt-BR\&ct=clnk\&gl=br> . Acesso em: 25 set 2016.

FONSECA, Marcelo da. Nossa história: Minas Gerais é o berço da legislação mineral. Disponível em: <http://www.em.com.br/app/noticia/politica/2014/11/08/interna_politica,587993/nossa-historiaminas-gerais-e-o-berco-da-legislacao-mineral.shtml>. Acesso em: 24 set 2016.

GAZIZINELLI, Gustavo; RIBEIRO, Gabriel; GENEROSO; Patrícia. Minerodutos: um cheque em branco para o desenvolvimento do país. Entrevista concedida por e-mail a IHU On-Line, 07 jan 2016. Disponível em:<http://cartamaior.com.br/?/Editoria/Meio-Ambiente/Minerodutos-um-chequeem-branco-para-o-desenvolvimento-do-pais/3/35281>. Acesso em: 24 set 2016. 
GUSTIN, Miracy Barbosa de Sousa; SANTOS, Boaventura de Sousa. Impactos da Mineração na região de Conceição do Mato Dentro. Projeto Internacional de Pesquisa Cidade e Alteridade, iniciativa conjunta da UFMG, da UFV, da UI e do CES/UC. Disponível em: <http://cimos.blog.br/wpcontent/uploads/2013/08/RELAT\%C3\%93RIO-5_CONCEI\%C3\%87\%C3\%83O-DO-MATODENTRO.pdf>. Acesso em: 24 set 2016.

GUSTIN, Miracy Barbosa de Sousa; SANTOS, Boaventura de Sousa. Impactos da Mineração na região de Conceição do Mato Dentro. Relatório sobre os impactos da mineração e as mudanças no contexto Urbano de Conceição do Mato Dentro, Brasil Relatório Final. Belo Horizonte, 2014. Disponível em: <http://docplayer.com.br/1858332-Relatorio-sobre-os-impactos-da-mineracao-e-asmudancas-no-contexto-urbano-de-conceicao-do-mato-dentro-mg-brasil-relatorio-final.html >. Acesso em: 24 set 2016.

HAJE, Lara. Mortalidade por acidente de trabalho em setor de mineração é muito alta, diz pesquisador, 2014. Câmara Notícias. Disponível em:

<http://www2.camara.leg.br/camaranoticias/noticias/ECONOMIA/473712- MORTALIDADE-PORACIDENTE-DE-TRABALHO-EM-SETOR-DE-MINERACAO-E-MUITO-ALTA,- DIZ PESQUISADOR.html>. Acesso em: 24 set. 2016.

MINERADORA é autuada por trabalho análogo à escravidão em Minas. G1 MG, 25/04/2014 <http://g1.globo.com/minas-gerais/noticia/2014/04/mineradora-e-autuada-por trabalho-analogoescravidao-em-minas.html>

MORAIS, Flaviane Barros Bolzan de. Compliance e o cenário brasileiro após a regulamentação da lei anticorrupção. Disponível em:

<http://www.migalhas.com.br/dePeso/16,MI226699,31047Compliance+e+o+cenario+brasileiro+apos +a+regulamentacao+da+lei>. Acesso em: 7 set 2016.

NEGRÃO, Célia Regina P.Lima; PONTELO, Juliana de Fátima Pontelo. Os Reflexos da Lei n. ${ }^{\mathbf{0}}$ 12.846/2013, conhecida como Lei Anticorrupção na Administração Pública. Disponível em: <https://www.correios.com.br/sobre-correios/a-empresa/revista-de-estudo-de-direito-postal-daect/edicao-atual/pdf/2OSREFLEXOSDALEI_verso11_11_2015.pdf>. Acesso em: 07 set 2016.

RESENDE, M. E. F.; VILLALTA, L. C. As Minas setecentistas. Belo Horizonte: Companhia do tempo: Autêntica, 2007.

PAMPLONA, Rodolfo. Terceirização e responsabilidade patrimonial da administração pública. Salvador. Revista Diálogo Jurídico, 2002, nº 11, p. 36.

PEDROSA, Ana Paula; ARIADNE, Queila. Anglo American é autuada por trabalho análogo à escravidão. O Tempo, Belo Horizonte, 24/04/2014. Disponível em:

$<$ http://www.otempo.com.br/capa/economia/anglo-american-\%C3\% A9-autuada-por-trabalhoan\%C3\%A1logo-\%C3\%A0-escravid\%C3\%A3o-1.827736>. Acesso em: 24 set 2016.

PEIXOTO, Paulo. Gigante da mineração é autuada por trabalho análogo à escravidão em MG. Mercado. Folha de S. Paulo, 24/04/2014. <http://www1.folha.uol.com.br/mercado/2014/04/1445055gigante-da-mineracao-e-autuada-por-trabalho-analogo-a-escravidao-em-mg.shtml >.Acesso em: 24 set 2016.

PORTO, Eduardo. Terreno minado. Época Negócios, São Paulo, 5 abr. 2010. Disponível em: <http://epocanegocios.globo.com/Revista/Common/0EMI131170-16642,00-

TERRENO+MINADO.html>. Acesso em: 24 set 2016. 
SALIM, Celso; EMIDIO, Aline Riquetti Campos; ROCHA, Paula Mendes Werneck da.

Identificação, mensuração e análise dos acidentes, doenças e mortes no setor mineral: construção de modelo de monitoramento das condições de trabalho e saúde dos trabalhadores das minerações. Belo Horizonte: Fundacentro / CNI, 2013. (Relatório de Pesquisa).Disponível em: <http://ftp.medicina.ufmg.br/osat/arquivos/RelatorioAt_30092014.pdf >. Acesso em: 24 set. 2016. p. 68 .

SEGUROS da Construção. Disponível em:<http://www.ebanataw.com.br/roberto/seguros/segciv0.htm>. Acesso em: 25 set 2016.

TÔRRES, Mariana Abreu. Histórias de água e minério: os efeitos do Projeto Minas-Rio em Água Quente, Conceição do Mato Dentro. Disponível em: <http://conflitosambientaismg.lcc.ufmg.br/wpcontent/uploads/2014/12/Monografia-Marina-Abreu-Efeitos-do-Projeto-Minas-Rio.pdf >. Acesso em: 24 set 2016. p. 25.

TRABALHADORES do Porto Açu entram em greve. Portal G1. Disponível em: < http://g1.globo.com/economia/noticia/2011/03/trabalhadores-do-porto-do-acu-entram-em-greve.html>. Acesso em: 24 set 2016.

ZHOURI, Andréa. "Estudo de Atualização das Áreas de Influência (AI) do Projeto Minas-Rio Mineração", elaborado pela empresa de consultoria Ferreira Rocha Gestão de Projetos Sustentáveis. Grupo de Estudos em Temáticas Ambientais (GESTA - UFMG). Disponível em: <https://webcache.googleusercontent.com/search?q=cache:NQM_Ck1RjAJ:https://conflitosambientais mg.lcc.ufmg.br/wp-content/uploads/2015/09/Parecer-GESTA-sobre-Relat\%25C3\%25B3rio-FerreiraRocha-2014-VF.pdf+\&cd=1\&hl=pt-BR\&ct=clnk\&gl=br $>$. Acesso em: 24 set 2016.

WROBLESKI, Stefano. Fiscalização volta a flagrar escravidão em megaobra da Anglo American. Repórter Brasil, 17/05/2014. Disponível em: <http://reporterbrasil.org.br/2014/05/fiscalizacao-voltaa-flagrar-escravidao-em-megaobra-da-anglo-american/>;

WROBLESKI, Stefano. Imigrantes haitianos são escravizados no Brasil. Repórter Brasil, 23/01/2014; <http://reporterbrasil.org.br/2014/01/imigrantes-haitianos-sao-escravizados-no-brasil/> 